\title{
EXPERIMENTAL EVALUATION OF WEDM MACHINED SURFACE WAVINESS
}

\author{
Katerina Mouralova*, Jiri Kovar, Pavel Houska
}

\author{
Brno University of Technology, Faculty of Mechanical Engineering, Technicka 2896/2, 61669 Brno, Czech \\ Republic \\ * corresponding author: mouralova@fme.vutbr.cz
}

Abstract. Wire Electrical Discharge Machining (WEDM) an unconventional machining technology which has become indispensable in many industries. The typical morphology of a surface machined using the electrical discharge technology is characterized with a large number of craters caused by electro-spark discharges produced during the machining process. The study deals with an evaluation of the machine parameter setting on the profile parameters of surface waviness on samples made of two metal materials Al 99.5 and Ti-6Al-4V. Attention was also paid to an evaluation of the surface morphology using 3D colour filtered and non-filtered images.

KEYWORDS: WEDM; electrical discharge machining; titanium alloy Ti-6Al-4V; aluminium Al 99.5; waviness.

\section{INTRODUCTION}

The physical substance of stock removal in the electroerosion process is in periodically acting electrical discharges between the tool electrode and the workpiece. The erosion process alone takes place in a dielectric medium - a liquid with high electric resistance. Microscopic particles are washed away by dielectric medium and small craters are formed on the workpiece surface. Wire electrical discharge machining (WEDM), the diagram of which is in Fig. 1. is one of the most productive electro-erosion applications. There are no limiting mechanical properties of the machined material such as toughness or high hardness and only electric conductivity is necessary. The tool is a continuously unwinding wire electrode, removing material in all directions and its geometry does not change like in conventional machining methods [1,2].

Mahapatra [3] focused on the significant machining parameters (metal removal rate, kerf and surface finish) for the performance measures in the WEDM. It was proved that every performance measure requires different combination of these factors for its optimization. For their experiment, the nonlinear regression analysis (for the study of the relationship between control factors and responses) and the genetic algorithm (for the WEDM process optimization with multiple objectives) were employed. The experiments demonstrated the ability of WEDM process parameters to be adjustable for reaching better above mentioned significant machining parameters (metal removal rate, surface finish and kerf). Sarkar [4] investigated the optimization of WEDM of gamma titanium aluminide by employing the artificial neural network modelling. According to the outcomes of the experiments done and due to the overall optimization strategy and the

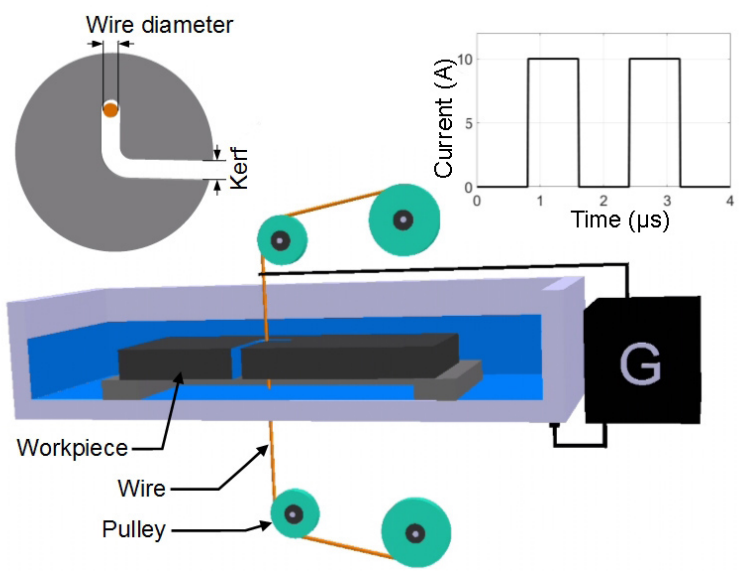

FiguRE 1. Diagram of wire electrical discharge machining process.

combination of single and multipass cutting operations, a new novel concept of critical surface roughness and effective cutting speed was obtained for the machining process selection in order to reach its maximum productivity. They focused on the influential force of four process parameters (namely, pulse on time, peak current, dielectric flow rate, and effective wire offset) on the process performance.

There are many factors which have a substantial influence on the quality of the machined surface and they can be found using various methods [5,6]. Although machine setting parameters are a significant factor, it is the material characteristics of the workpiece that define the final surface quality. The surface quality parameters are influenced by a set of physical and mechanical characteristics of the machined material and the type of its heat treatment [7]. 


\begin{tabular}{lccccc}
\hline Contents & $\mathrm{Si}$ & $\mathrm{Fe}$ & $\mathrm{Cu}$ & $\mathrm{Zn}$ & $\mathrm{Ti}$ \\
\hline Max. (wt\%) & 0.3 & 0.4 & 0.05 & 0.07 & 0.05 \\
\hline
\end{tabular}

TABle 1. Chemical composition of aluminium Al 99.5 prescribed by standard.

\begin{tabular}{lcccc}
\hline Contents & $\mathrm{Al}$ & $\mathrm{Fe}$ & $\mathrm{O}$ & $\mathrm{V}$ \\
\hline Min. (wt\%) & 5.5 & - & - & 3.5 \\
Max. (wt\%) & 6.75 & 0.25 & 0.2 & 4.5 \\
\hline
\end{tabular}

\begin{tabular}{c} 
Heat treatment (HT) \\
\hline Quenched and tempered \\
$940^{\circ} \mathrm{C} / 45 \mathrm{~min} /$ water \\
$500{ }^{\circ} \mathrm{C} / 2 \mathrm{~h} /$ air \\
\hline
\end{tabular}

TABle 2. Chemical composition of titanium alloy Ti$6 \mathrm{Al}-4 \mathrm{~V}$ prescribed by standard and one type of heat treatment.

\section{EXPERIMENTAL SETUP AND MATERIAL}

\subsection{EXPERIMENTAL MATERIAL}

Samples for the experiment were made of pure aluminium Al 99.5 and titanium alloy Ti-6Al-4V. Aluminium $\mathrm{Al} 99.5$ is a material with low specific weight. Its indisputable advantages include excellent corrosion resistance, good weldability and suitability for anodizing with hardness $15 \mathrm{HB}$, tensile strength 65$160 \mathrm{MPa}$, and chemical composition, see Tab. 1. It is used almost in all industrial sectors for structural elements and units that are low mechanically stressed, requiring a highly ductile material with high corrosion resistance, which is very well thermally and electrically conductive [8]. Basically, it can be welded using any method [9]. The experiment used an initial rod $20 \mathrm{~mm}$ in diameter out of which a square-shaped material was made by the electro-erosion machining.

Titanium alloy Ti-6Al-4V with chemical composition shown in Tab. 2 was used in two sets. The first set - material without additional heat treatment, the second set - with heat treatment, see Tab. 2 This alloy has a high tensile strength of $900 \mathrm{MPa}$ and an excellent corrosion resistance. It has the highest strength to specific weight ratio of all metal materials [10]. It has a high biocompatibility and capacity to resist thermal loads up to a temperature of $315^{\circ} \mathrm{C}$. It is used for manufacturing constructional parts of weapons and aircraft, turbine blades, fasteners, medical and dental implants, and sport equipment [11]. The experiment used an initial square-shaped material $18 \mathrm{~mm}$ in thickness. For the purpose of increasing the hardness, heat treatment was carried out.

ZHR 4150AK hardness tester, series Rockwell by Zwick Roell was used for the measurement of hardness of sample material. For titanium alloy, a hardness of $46 \mathrm{HRC}(432 \mathrm{HB})$ was measured.

\begin{tabular}{|c|c|c|c|c|c|}
\hline $\begin{array}{l}\text { Sample } \\
\text { number }\end{array}$ & $\begin{array}{l}\text { GV } \\
(\mathrm{V})\end{array}$ & $\begin{array}{l}T_{\text {on }} \\
(\mu \mathrm{s})\end{array}$ & $\begin{array}{l}T_{\text {off }} \\
(\mu \mathrm{s})\end{array}$ & $\begin{array}{c}\text { WOT } \\
(\mathrm{m} / \mathrm{min})\end{array}$ & $\begin{array}{l}\text { DC } \\
\text { (A) }\end{array}$ \\
\hline 1 & 70 & 8 & 40 & 12 & 30 \\
\hline 2 & 60 & 8 & 30 & 12 & 30 \\
\hline 3 & 60 & 8 & 40 & 12 & 25 \\
\hline 4 & 60 & 10 & 40 & 12 & 30 \\
\hline 5 & 50 & 8 & 40 & 12 & 30 \\
\hline 6 & 60 & 8 & 50 & 12 & 30 \\
\hline 7 & 60 & 6 & 40 & 12 & 30 \\
\hline 8 & 60 & 8 & 40 & 12 & 35 \\
\hline 9 & 60 & 8 & 40 & 10 & 30 \\
\hline 10 & 60 & 8 & 40 & 14 & 30 \\
\hline 11 & 60 & 8 & 40 & 12 & 30 \\
\hline 12 & 50 & 6 & 30 & 10 & 35 \\
\hline 13 & 70 & 10 & 50 & 10 & 25 \\
\hline 14 & 70 & 10 & 30 & 10 & 35 \\
\hline 15 & 60 & 8 & 40 & 12 & 30 \\
\hline 16 & 70 & 6 & 50 & 10 & 35 \\
\hline 17 & 70 & 10 & 50 & 14 & 35 \\
\hline 18 & 60 & 8 & 40 & 12 & 30 \\
\hline 19 & 60 & 8 & 40 & 12 & 30 \\
\hline 20 & 70 & 6 & 50 & 14 & 25 \\
\hline 21 & 50 & 6 & 30 & 14 & 25 \\
\hline 22 & 60 & 8 & 40 & 12 & 30 \\
\hline 23 & 70 & 10 & 30 & 14 & 25 \\
\hline 24 & 50 & 6 & 50 & 10 & 25 \\
\hline 25 & 60 & 8 & 40 & 12 & 30 \\
\hline 26 & 50 & 10 & 50 & 14 & 25 \\
\hline 27 & 50 & 10 & 30 & 10 & 25 \\
\hline 28 & 50 & 6 & 50 & 14 & 35 \\
\hline 29 & 50 & 10 & 50 & 10 & 35 \\
\hline 30 & 70 & 6 & 30 & 14 & 35 \\
\hline 31 & 50 & 10 & 30 & 14 & 35 \\
\hline 32 & 60 & 8 & 40 & 12 & 30 \\
\hline 33 & 70 & 6 & 30 & 10 & 25 \\
\hline
\end{tabular}

TABLE 3. Machining parameters used in the experiments. GV - gap voltage; WOT - wire off time; DC discharge current.

\subsection{WEDM MACHINE SETUP}

The WEDM machine used in this study was high precision five axis CNC machine MAKINO EU64. As electrode, a brass wire $(60 \% \mathrm{Cu}$ and $40 \% \mathrm{Zn})$ PENTA CUT E with a diameter of $0.25 \mathrm{~mm}$ was used. Samples were immersed in the deionized water which served as dielectric media and also removed debris in the gap between the wire electrode and the workpiece during the process. To find out the effects of parameters of gap voltage, pulse on $\left(T_{\text {on }}\right)$ and off time $\left(T_{\text {off }}\right)$, wire feed and discharge current on the machined surface, their different setting (Tab. 3.) was used for each of 33 samples made of individual materials. The values of individual parameter settings were determined on the basis of previous tests [12]. 


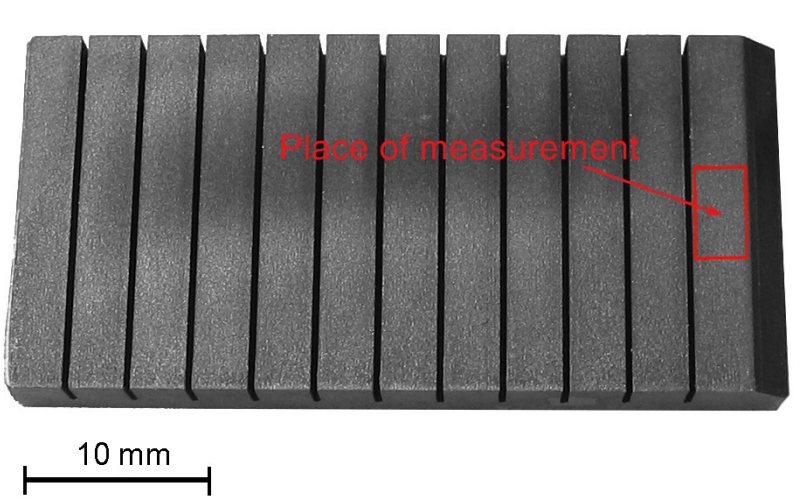

FiguRE 2. Waviness measurement area on each sample (sample of titanium alloy).

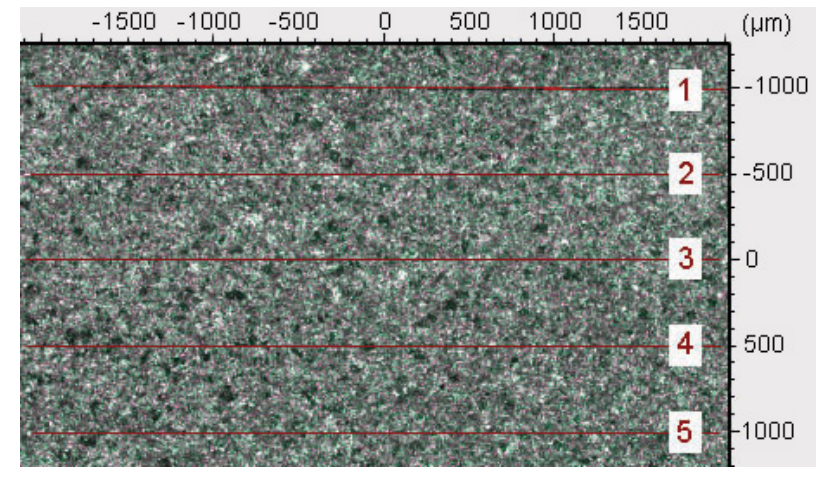

Figure 3. Position of distribution of areas for waviness measurement.

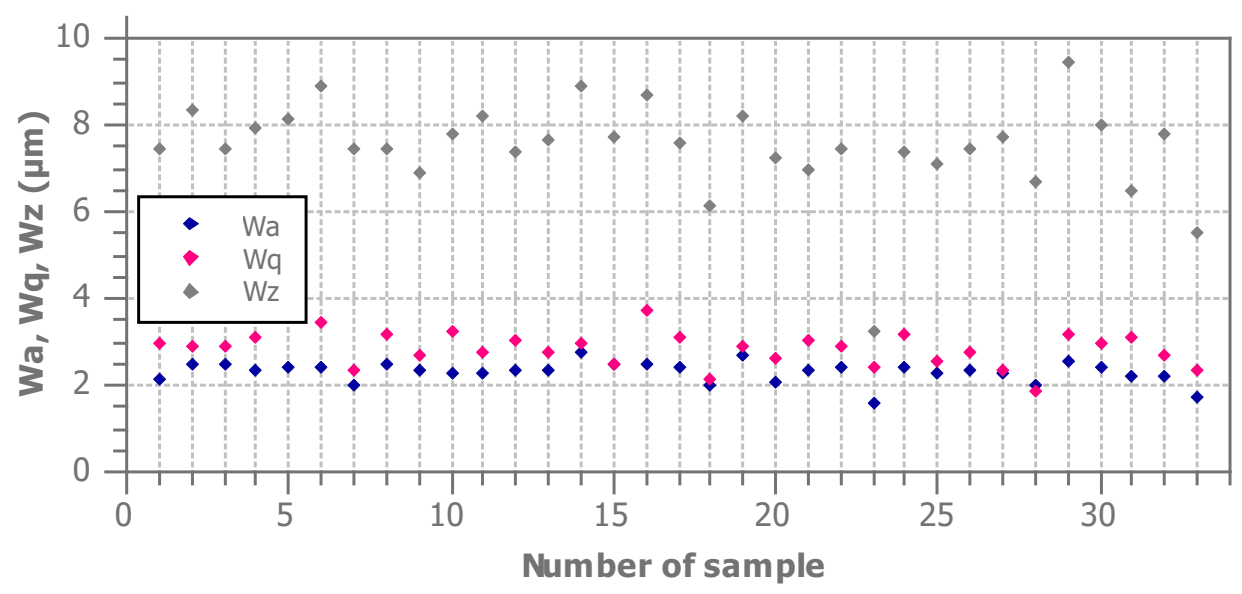

Figure 4. Average values Wa, Wq and Wz of samples made of $\mathrm{Al} 99.5$.

For the experiment, a "half response surface design" containing 33 runs grouped in two blocks (Tab. 3) was chosen. In order to reduce the possibility of systematic errors, the individual runs are randomised; besides that, 7 central points were added to the experiment to ensure a better measure of error. This plan of data collection has been described in detail, for example, by Montgomery [13].

\section{Results OF EXPERIMENT}

The morphology and parameters of waviness of the machined surface were studied using the contactless measuring instrument from IFM G4 from Alicona. The measured data were analyzed using the software IF-Laboratory Measurement supplied by Alicona. The term profile waviness is defined by a curvature that shows a certain periodicity - waving.

The area of waviness measurement on each sample is shown in Fig. 2 In this area, waviness measurement was carried out according to ISO 4287 [14] on straight lines $4.2 \mathrm{~mm}$ long, always at exactly defined distances from one another as shown in Fig. 3 The waviness parameters evaluated by profile method were maximum height of the waviness profile $\mathrm{Wz}$, arithmetic average of waviness Wa and root mean square deviation of the waviness profile $\mathrm{Wq}$.

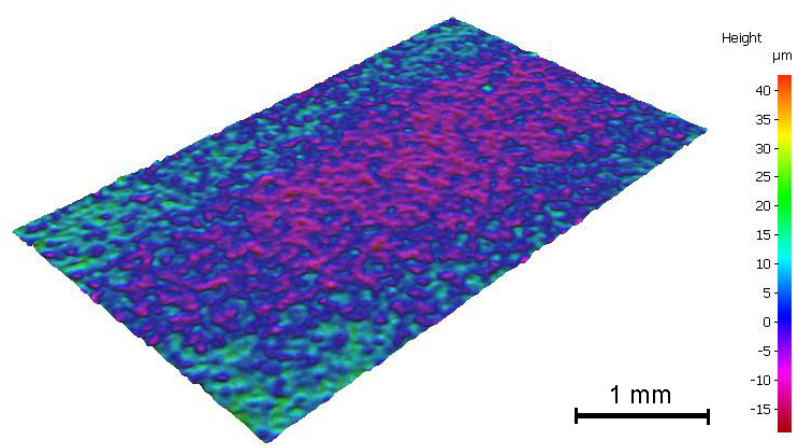

Figure 5. Colour filtered image of the surface of sample $23,2.5 \times$ magnified (voltage $70 \mathrm{~V}, T_{\text {on }}=10 \mu \mathrm{s}$, $T_{\text {off }}=30 \mu \mathrm{s}$, wire feed $14 \mathrm{~m} / \mathrm{min}$, current $\left.25 \mathrm{~A}\right)$.

\subsection{The Results of the Profile WAViness MEASUREMENTS ON SAMPLES MADE OF AL 99.5}

The measured values of the waviness parameters Wa, Wz and Wq were processed into Fig. 4. Each of the parameters was measured in 5 points on each sample and then the average value was calculated.

The measured values of the waviness parameter Wa range in an interval from $1.56 \mu \mathrm{m}$ (sample 23) to $2.75 \mu \mathrm{m}$ (sample 14). The average value $\mathrm{Wq}$ in 


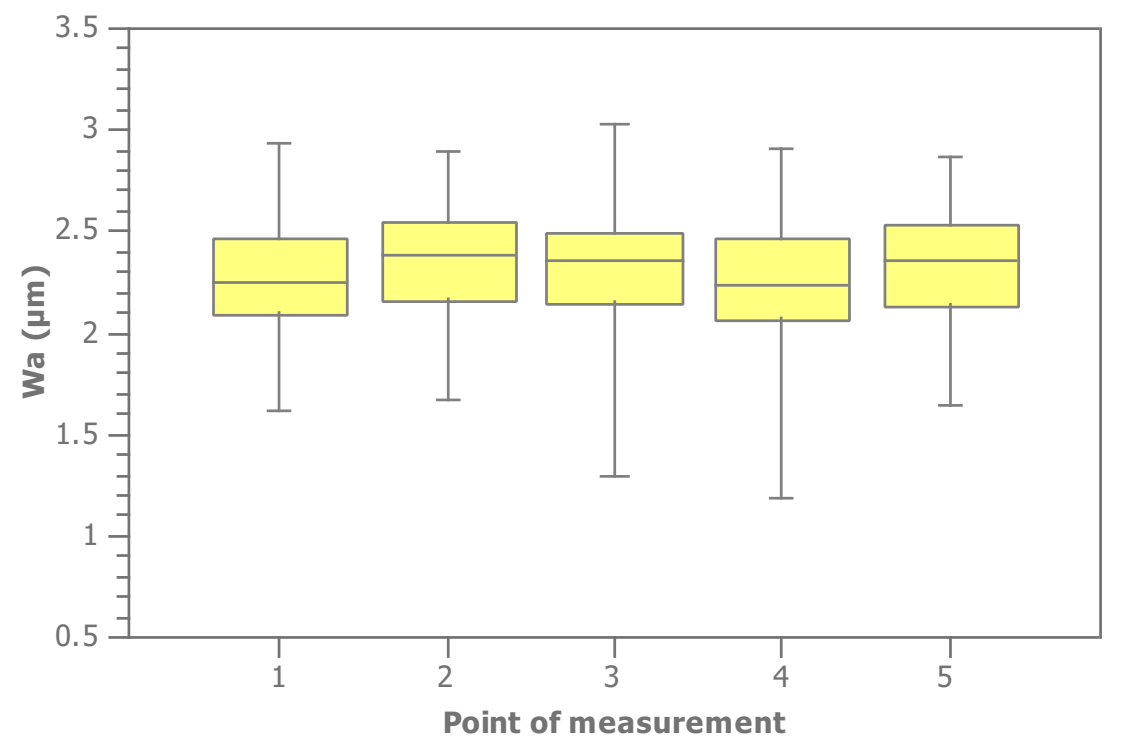

Figure 6. Values Wa in individual points of measurement on all samples made of Al 99.5.

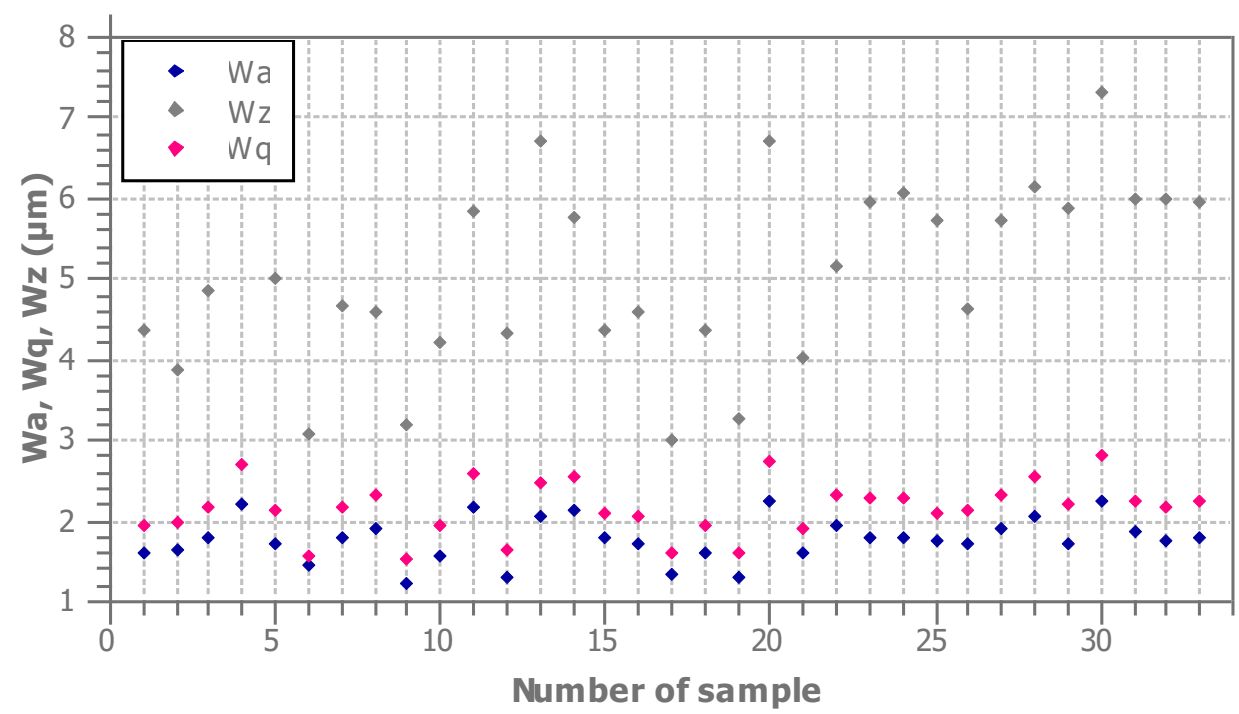

Figure 7. Average values $\mathrm{Wa}, \mathrm{Wq}$ and $\mathrm{Wz}$ of samples made of titanium alloy Ti-6Al-4V.

measured samples was $2.85 \mu \mathrm{m}$ and for $\mathrm{Wz}$ it was $7.48 \mu \mathrm{m}$. Overall, sample 23 has the lowest values of all measured parameters $\mathrm{Wa}=1.56 \mu \mathrm{m}, \mathrm{Wq}=1.88 \mu \mathrm{m}$ and $\mathrm{Wz}=3.23 \mu \mathrm{m}$ and its surface is shown in Fig. 5

A box graph (Fig. 6) was compiled of all measured values Wa in individual points on samples according to Fig. 3. The average measured value Wa does not differ significantly in individual points of measurement. Only the maximum and minimum values measured in individual points are different. The lowest values were measured in the middle of the sample in points 3 and 4 .

\subsection{The Results of THE PROFile WAVINESS MEASUREMENTS ON SAMPLES MADE OF TITANIUM ALLOY TI-6AL-4V}

The average values of waviness parameters in 5 points on the surfaces of samples made of titanium alloy were processed into Fig. 77. The minimum measured

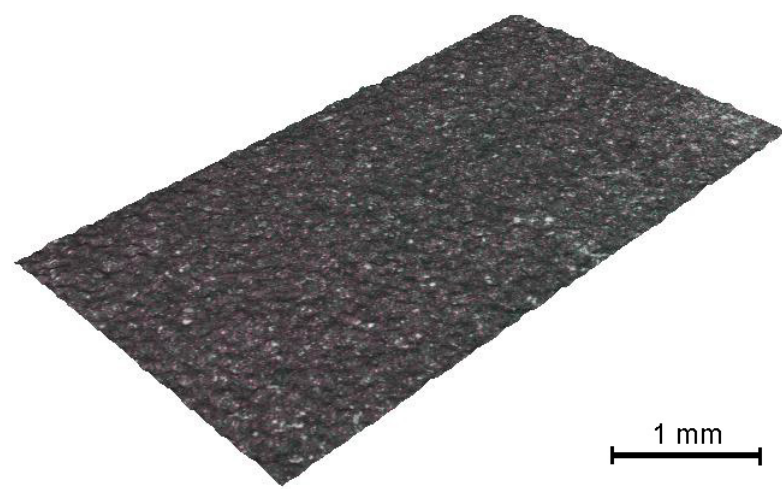

FIgURE 8 . Non-filtered image of the surface of sample $30,2.5 \times$ magnified $\left(\right.$ voltage $70 \mathrm{~V}, T_{\text {on }}=6 \mu \mathrm{s}, T_{\text {off }}=$ $30 \mathrm{\mu s}$, wire feed $14 \mathrm{~m} / \mathrm{min}$, current $35 \mathrm{~A}$ ).

value of the waviness parameter Wa was in sample 9 , specifically $1.21 \mu \mathrm{m}$, and the maximum in sample 20 , 


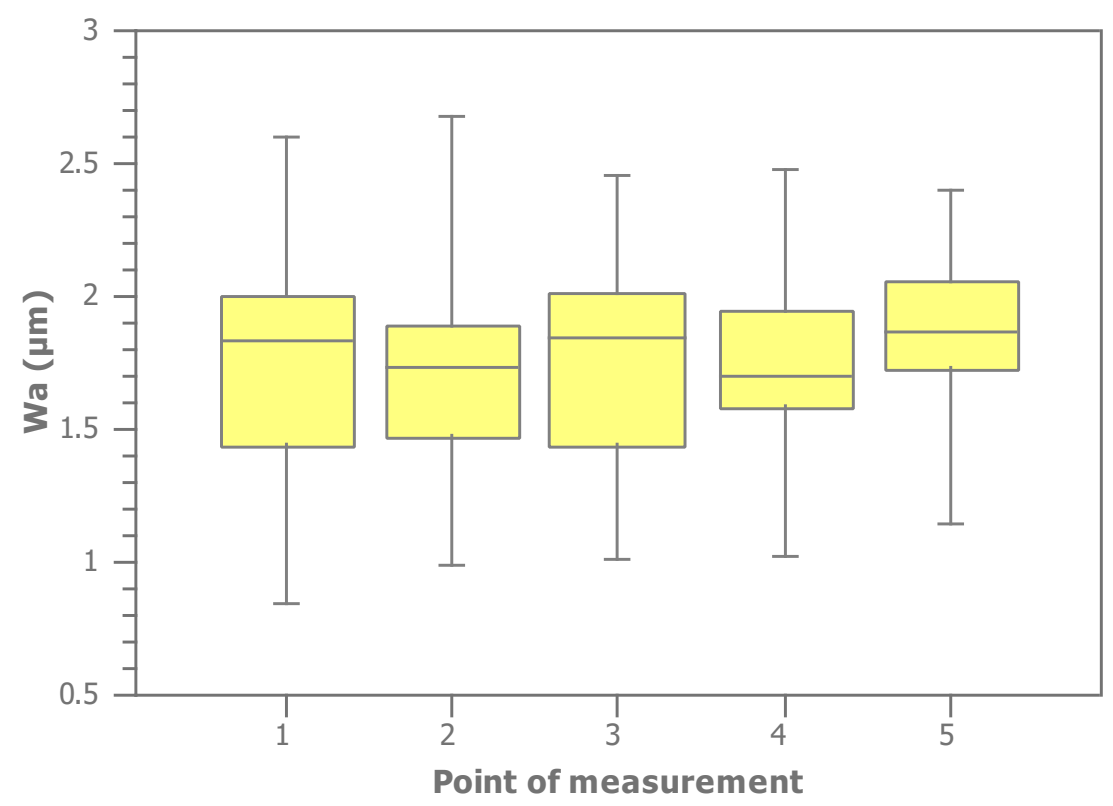

Figure 9. Values Wa in individual points of measurement on all samples made of titanium alloy Ti-6Al-4V.

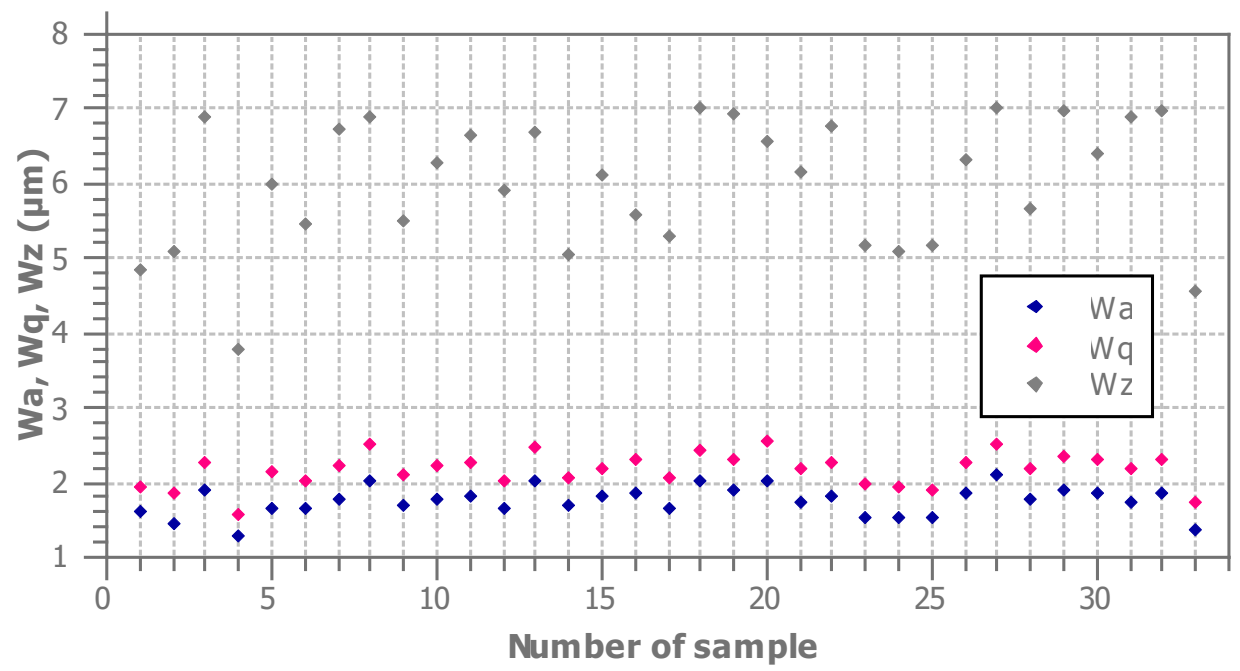

Figure 10. Average values Wa, Wq and $\mathrm{Wz}$ of samples made of titanium alloy Ti-6Al-4V with heat treatment.

specifically $2.26 \mu \mathrm{m}$. The average value $\mathrm{Wq}$ in the measured samples was $2.16 \mu \mathrm{m}$ and for $\mathrm{Wz}$ it was $5.08 \mu \mathrm{m}$.

The maximum values of all of the three waviness parameters were for sample 30; its surface morphology is shown in Fig. 8

The parameter Wa was measured in 5 points on each sample and its values did not differ significantly in these different points, which is apparent from Fig. 9 . Nor in the parameters $\mathrm{Wq}$ and $\mathrm{Wz}$ was a significant deviation in individual points of measurement.

\subsection{The Results of the WAVIness Profile MEASUREMENTS ON SAMPLES MADE OF TITANIUM ALLOY TI-6AL-4V WITH HEAT TREATMENT}

The profile measurements of the surface waviness parameters of samples made of titanium alloy with heat treatment were processed into Fig. 10. The average value $\mathrm{Wq}$ of the measured samples was $2.17 \mu \mathrm{m}$ and for $\mathrm{Wz}$ it was $6.01 \mu \mathrm{m}$. The minimum measured value of the waviness parameter Wa was $1.3 \mu \mathrm{m}$ for sample 4 and the maximum was $2.08 \mu \mathrm{m}$ for sample 27 .

No significant deviation was found in any of the three examined waviness parameters in individual points of measurement. The values of parameter Wa in 5 points of measurement were compiled into Fig. 11 .

\section{Conclusions And discussion}

The morphology of sample surfaces is made up of a large number of craters which were formed by erosion process $[15,16]$. The profile parameters of the machined surface are dependent not only on the machine setting parameters [17], but also on the mechanical and physical properties of the machined material 


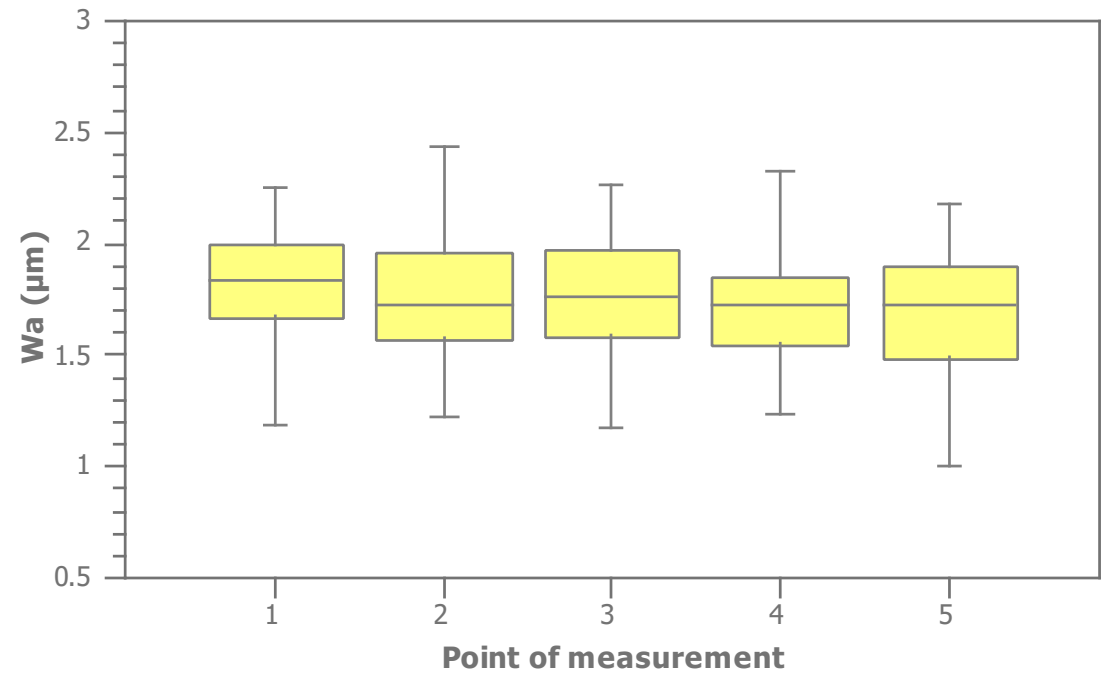

FIGURE 11. Values Wa in individual points of measurement on all samples made of titanium alloy Ti-6Al-4V with heat treatment.

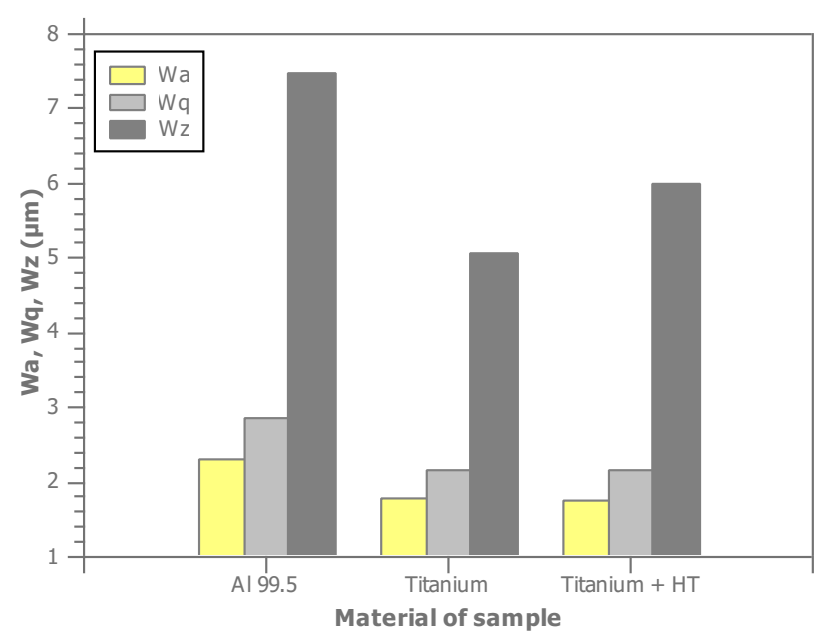

Figure 12. Average values of waviness parameters of individual sample sets of tested materials.

which are a direct consequence of the microstructure parameters of the studies materials [18].

The measured values of the surface waviness parameters are in accordance with literature $[19,20,21]$. It is evident from Fig. 12 that the maximum values Wa were measured in samples made of Al 99.5. The high values of Wa unequivocally relate to the low melting temperature of the material, low strength and with a relatively large grain size of the machined $\mathrm{Al}$ stock [22]. The surface of samples made of titanium alloys with and without heat treatment had almost the same average waviness value Wa, specifically 1.77 and $1.75 \mu \mathrm{m}$.

The average value of parameter $\mathrm{Wz}$ was highest in the set of samples made of $\mathrm{Al} 99.5$, specifically $7.48 \mathrm{\mu m}$. The average value of $\mathrm{Wz}$ of samples made of titanium alloy without heat treatment was lower by $1 \mu \mathrm{m}$ than of the samples made of the same material with additional heat treatment (quenched and tempered). This fact is quite in accordance with the rougher microstructure of the titanium sample after heat treatment.

The above-mentioned experiments quite clearly show that the profile parameters of surface waviness depend quite significantly not only on the setting of technological parameters during machining, but particularly on the chemical composition of the machined material and its mechanical properties after heat treatment. Effects of machining parameters are subject to a further research.

\section{ACKNOWLEDGEMENTS}

This work is an output of research and scientific activities of NETME Centre, supported through project NETME CENTRE PLUS (LO1202) by financial means from the Ministry of Education, Youth and Sports under the "National Sustainability Programme I".

This research work was supported by the BUT, Faculty of Mechanical Engineering, Brno, Specific research 2013, with the grant "Research of advanced technologies for competitive machinery", FSI-S-13-2138, ID 2138 and technical support of Intemac Solutions, Ltd., Kurim.

\section{REFERENCES}

[1] JAIN, Vijay Kumar. Advanced machining processes. Allied publishers, 2009, ISBN 8177642944.

[2] GHODSIYEH, Danial, GOLSHAN, Abolfazl, SHIRVANEHDEH, Jamal Azimi. Review on current research trends in wire electrical discharge machining (WEDM). Indian journal of science and technology, 2013, 6.2: pp. 4128-4140. DOI:10.17485/ijst/2013/v6i2/30595

[3] MAHAPATRA, S. S., PATNAIK, Amar. Optimization of wire electrical discharge machining (WEDM) process parameters using Taguchi method. The International Journal of Advanced Manufacturing Technology, 2007, pp. 911-925, DOI:10.1007/s00170-006-0672-6

[4] SARKAR, S., et al. An integrated approach to optimization of WEDM combining single-pass and multipass cutting operation. Materials and Manufacturing Processes, 2010, pp. 799-807, DOI:10.1080/10426910903575848 
[5] MATOUSEK, Radomil, Josef BEDNAR Grammatical Evolution: Epsilon Tube in Symbolic Regression Task. In MENDEL 2009, Mendel Journal series. MENDEL. Brno, BUT. pp. 9 - 15. ISBN 978-80-214-3884-2, ISSN 1803-3814.

[6] MATOUSEK, Radomil, Josef BEDNAR. Grammatical evolution and STE criterion: Statistical properties of STE objective function, Lecture Notes in Electrical Engineering, vol 68, pp. 131-142, DOI:10.1007/978-90-481-9419-3_11

[7] DAVIM, J. Paulo. Surface Integrity in Machining. 1st ed. London: Springer, 2010, 215 pp. ISBN 978-1-84882-873-5.

[8] NIINOMI, Mitsuo. Recent metallic materials for biomedical applications. Metallurgical and materials transactions A, 2002, pp. 477-486, DOI:10.1007/s11661-002-0109-2

[9] CAO, X., JAHAZI, M. Effect of welding speed on butt joint quality of $\mathrm{Ti}-6 \mathrm{Al}-4 \mathrm{~V}$ alloy welded using a highpower Nd: YAG laser. Optics and Lasers in Engineering, 2009, pp. 1231-1241, DOI:10.1016/j.optlaseng.2009.05.010

[10] ALHAZAA, A., KHAN, T. I., HAQ, I. Transient liquid phase (TLP) bonding of Al7075 to Ti-6Al-4V alloy. Materials characterization, 2010, pp. 312-317, DOI:10.1016/j.matchar.2009.12.014

[11] MARSH, Elizabeth. A Technological and Market Study on the Future Prospects for Titanium to the Year 2000. European Commission, 1996.

[12] MOURALOVA, Katerina. Moderní technologie drátového elektroerozivního řezání kovových slitin. Thesis. Brno: CERM, 2015. 98 pp. ISBN 80-214-2131-2. Dizertacní práce. VUT v Brne, FSI, ÚST.

[13] MONTGOMERY, Douglas C. Design and analysis of experiments. John Wiley \& Sons, 2008, ISBN 978-0-470-12866-4.

[14] ISO 4287. Geometrical Product Specifications (GPS)-Surface Texture: Profile Method-Terms, Definitions and Surface Texture Parameters. 1997.

[15] TOSUN, N., H. PIHTILI. The Effect of Cutting Parameters on Wire Crater Sizes in Wire EDM. The International Journal of Advanced Manufacturing
Technology. 2003, pp. 857-865.

DOI:10.1007/s00170-002-1404-1

[16] HAN, Fuzhu, Jun JIANG a Dingwen YU. Influence of machining parameters on surface roughness in finish cut of WEDM. The International Journal of Advanced Manufacturing Technology. 2007, pp. 538-546. DOI:10.1007/s00170-006-0629-9

[17] KUMAR, Anish, Vinod KUMAR a Jatinder KUMAR. Multi-response optimization of process parameters based on response surface methodology for pure titanium using WEDM process. The International Journal of Advanced Manufacturing Technology. 2007, pp. 538-546. DOI:10.1007/s00170-013-4861-9

[18] SOMASHEKHAR, Kodalagara Puttanarasaiah, Nottath RAMACHANDRAN a Jose MATHEW. Material removal characteristics of microslot (kerf) geometry in $\mu-W E D M$ on aluminum. The International Journal of Advanced Manufacturing Technology. 2007, pp. 538-546. DOI:10.1007/s00170-010-2645-Z

[19] SPEDDING, T.A a Z.Q WANG. Study on modeling of wire EDM process. Journal of Materials Processing Technology. 1997, pp. 18-28. DOI:10.1016/S0924-0136(96)00033-7

[20] SERWIŃSKI, Radoslaw. THE WIRE ELECTRO DISCHARGE MACHINE SETTING PARAMETERS ANALYSIS INFLUENCING THE MACHINED SURFACE ROUGHNESS AND WAVINESS. Prace Instytutu Lotnictwa, 2009, pp. 168-175.

[21] PADHI, P.C., S.S. MAHAPATRA, S.N. YADAV a D.K. TRIPATHY. Performance characteristic prediction of WEDM process using response surface methodology and artificial neural network. Journal of Materials Processing Technology. 1997, pp. 18-28. DOI:10.1504/IJISE.2014.065616

[22] HASÇALIK, Ahmet, ÇAYDAŞ, Ulaş. Electrical discharge machining of titanium alloy (Ti-6Al-4V). Applied Surface Science, 2007, pp. 9007-9016, DOI:10.1016/j.apsusc.2007.05.031 